\title{
APPLICATION OF GPU SMOOTH PARTICLE HYDRODYNAMICS: WAVE RUNUP AND OVERTOPPING ON COMPOSITE SLOPES
}

\author{
Billy L. Edge ${ }^{1}$, Margery F. Overton ${ }^{2}$, Robert A. Dalrymple ${ }^{3}$, Alexis. Hérault ${ }^{4}$, Giuseppe Bilotta ${ }^{5}$, M. \\ Onur Kurum $^{6}$, Kevin Gamiel ${ }^{7}$
}

\begin{abstract}
Smooth Particle Hydrodynamics is a Lagrangian meshless numerical method with substantially improved capabilities in simulation of both fluid dynamics and solid mechanics due to its meshless nature. GPUSPH is an implementation of Smoothed Particle Hydrodynamics (SPH) on Nvidia CUDA-enabled (graphics) cards. In this paper the GPUSPH is applied to runup and overtopping applications and compared with experimental results from Roos and Battjes for a plane slope and Oaks, Edge and Lynett for complex bathymetry representing a complex levee transition. Results for both models show good comparison with experimental data and suggest GPUSPH as a reasonable tool for complex runup and overtopping problems.
\end{abstract}

Keywords: runup, overtopping, smooth particle hydrodynamics, GPUSPH

\section{INTRODUCTION}

Predicting nearshore processes has become increasingly important for assessing the impact of natural and anthropogenic impacts in the coastal zone. With the advance of computational capabilities and better understanding of the nearshore processes, numerical modeling has become a viable and effective way of simulating the coastal response. Smoothed Particle Hydrodynamics (SPH) based models like SPHysics and GPUSPH allow the solution of highly nonlinear complex fluid dynamics problems (e.g., plunging breakers and the random nature of turbulence) where it may not be possible to achieve a steady and meaningful analytical solution (Weiss et al. 2010). This research uses GPUSPH at the sea-beach or sea-structure interface with the goal of better understanding the relationship of the nearshore bathymetry and beach face topography on runup and overtopping processes occurring during storms and surge conditions.

\section{METHODOLOGY}

In order to validate GPUSPH for the problems described above, a comparison of the regular and irregular wave runup from large model tests such as that from Saville (1962) and Roos and Battjes (1976) have been used. The validation tests began using mild (dissipative) slopes with no complex nearshore features such as berms and composite slopes. Comparisons have also been made with Boussinesq wave models for complex shapes. The problem then progressed to conditions of complex geometry reflective of levees which have transitions from one type to another with changes in slopes, elevations and types.

\section{THE MODEL}

The SPHysics model and GPUSPH both are based upon the concept of Smoothed Particle Hydrodynamics for free surface flows as described originally by Monaghan (1994). Smoothed Particle Hydrodynamics (SPH) is a Lagrangian meshless numerical method that was developed in astrophysics in 1977 as described by Monaghan who was the first to apply it to free surface flows. SPH has substantially improved capabilities in simulation of both fluid dynamics and solid mechanics due to its meshless nature. The meshless Lagrangian method is particularly adaptable to wave problems including breaking waves. The methodology became more widespread following the works of GomezGesteira and Dalrymple (2004) and Dalrymple and Rogers (2006), who presented the development of SPHysics which is available as open source. Initially the method was programmed in SPHysics (https://wiki.manchester.ac.uk/sphysics/index.php/Main_Page) using FORTRAN. As the number of particles has grown to represent more complex problems, attention turned to the parallel computational capability of cpu cores and graphical processor units that have been advanced initially for the gaming community to performance well in excess of cpu units.

Due to the rapid growth of high performance Graphics Processing Units (GPUs), significant efforts have gone towards modifying the SPHysics code to GPUSPH. Hérault et al. (2010) have contributed

\footnotetext{
${ }^{1}$ North Carolina State University and UNC-CSI, b-edge@tamu.edu

${ }^{2}$ North Carolina State University, overton@ncsu.edu

3 Johns Hopkins University, rad@jhu.edu

${ }^{4}$ Conservatoire National des Arts et Métiers, alexis.herault@cnam.fr

${ }^{5}$ Università degli Studi di Catania, bilotta@dmi.unict.it

${ }_{7}^{6}$ North Carolina State University, onurkurum@gmail.com

${ }^{7}$ UNC - Renessaince Computing Center, kgamiel@renci.edu
} 
to initial development of GPUSPH and have shown that it immediately opens up the scale of computing.

GPUSPH is an implementation of Smoothed Particle Hydrodynamics (SPH) on NVIDIA CUDAenabled (graphics) cards. More detail of this development is given by Weiss et al. (2010), Hérault, Bilotta, and Dalrymple (2010) and at the GPUSPH website:

http://www.ce.jhu.edu/dalrymple/GPUSPH/Home.html.

NVIDIA introduced the CUDA architecture for NVIDIA cards in 2007 that then allowed the computational power of modern GPUs to be fully exploited without the traditional use of graphical engines. Although serial execution does not provide improvement with GPU implementation with CUDA, the large multi-core structure of NVIDIA and other graphics cards makes an excellent platform for computing algorithms exhibiting a high level of parallelism, such as SPH. For such problems, a well-tuned GPU implementation can easily achieve two orders of magnitude in speed-up of standard single-core CPU implementations.

\section{BEACHES WITH BERMS}

Initially proof of concept simulations were successfully carried out to show that GPUSPH was robust enough to handle complex geometry and provide realistic wave breaking and runup details. The model domain consisted of a rectangular wave tank with a composite beach and dune system (Figure 1). Three slopes made up the nearshore beach and dune system (1:8.66 lower beach, 1:8.0 upper beach and 1:1.5 dune face). A berm of approximately $0.1 \mathrm{~m}$ separated the lower and upper beach. Particles filled the tank to a water level of $0.6 \mathrm{~m}$ bringing the still water level (SWL) up on the face of the dune (or face of the structure) simulating an instance during the storm of elevated storm surge (Figure 2) on a dune face. Waves were generated using a deep-set, flap wave maker.

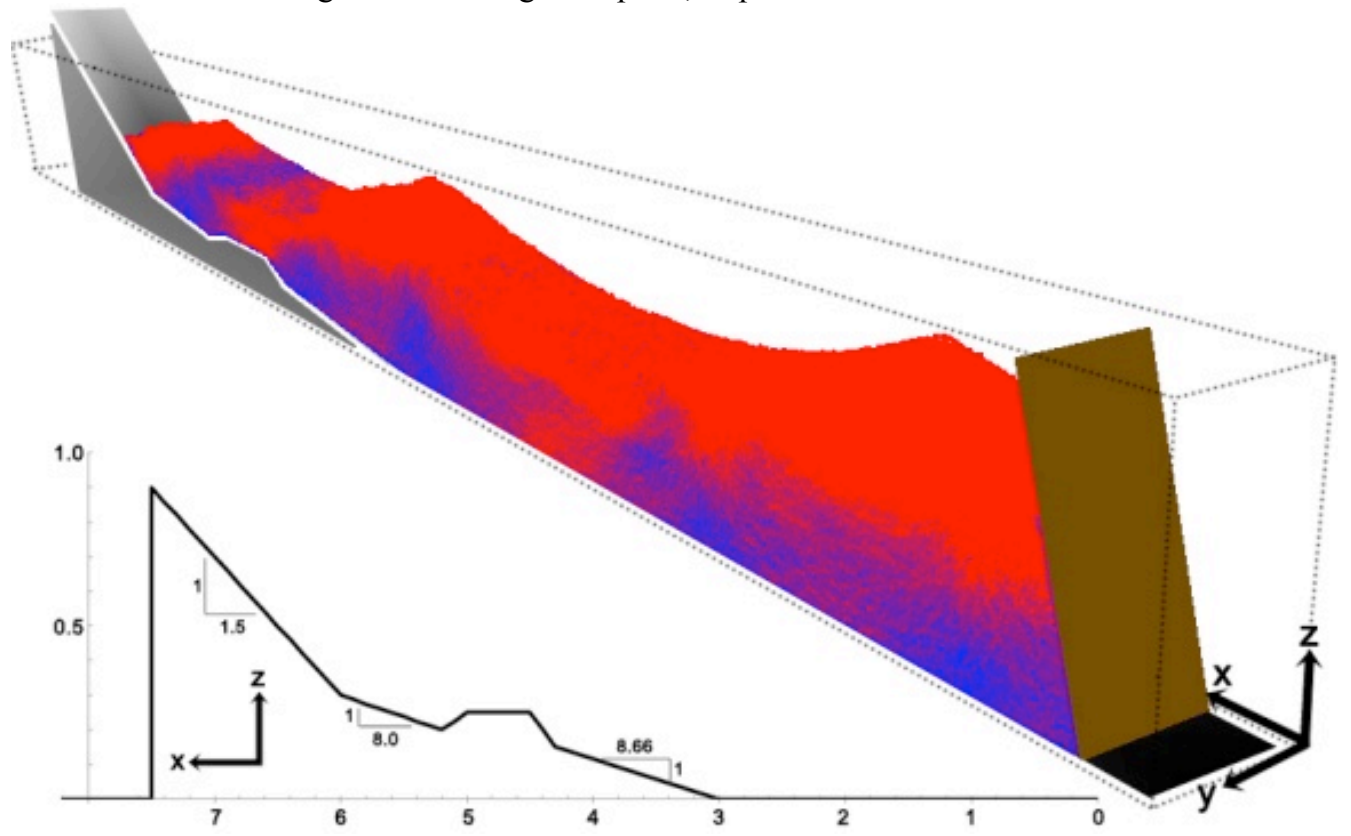

Figure 1. GPUSPH model domain (3D)

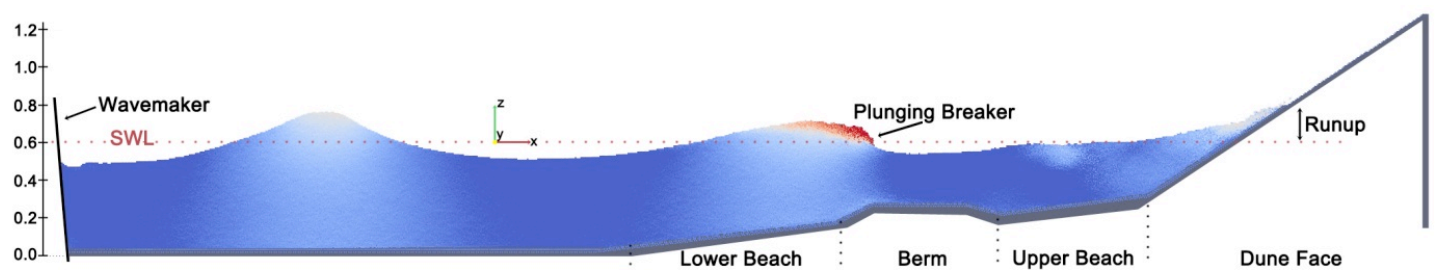

Figure 2. GPUSPH model domain (2D) 
The wave maker generated a wave seaward of the berm with a wave height of approximately $\mathrm{H}=$ $0.27 \mathrm{~m}$ and a wave period of 1.3 seconds. As shown in Figure 2, the plunging wave develops at the seaward edge of the berm leading to the reformation of the wave over the upper beach before running up the face of the dune to a height of about $0.3 \mathrm{~m}$ relative to SWL. These results encourage the use of GPUSPH for the study of nearshore processes including wave runup and overtopping. Figure 3 is an example of the same conditions when overtopping begins. Although this is a fixed beach, there is potential for incorporation of deformation with an appropriate scour or sediment transport model.

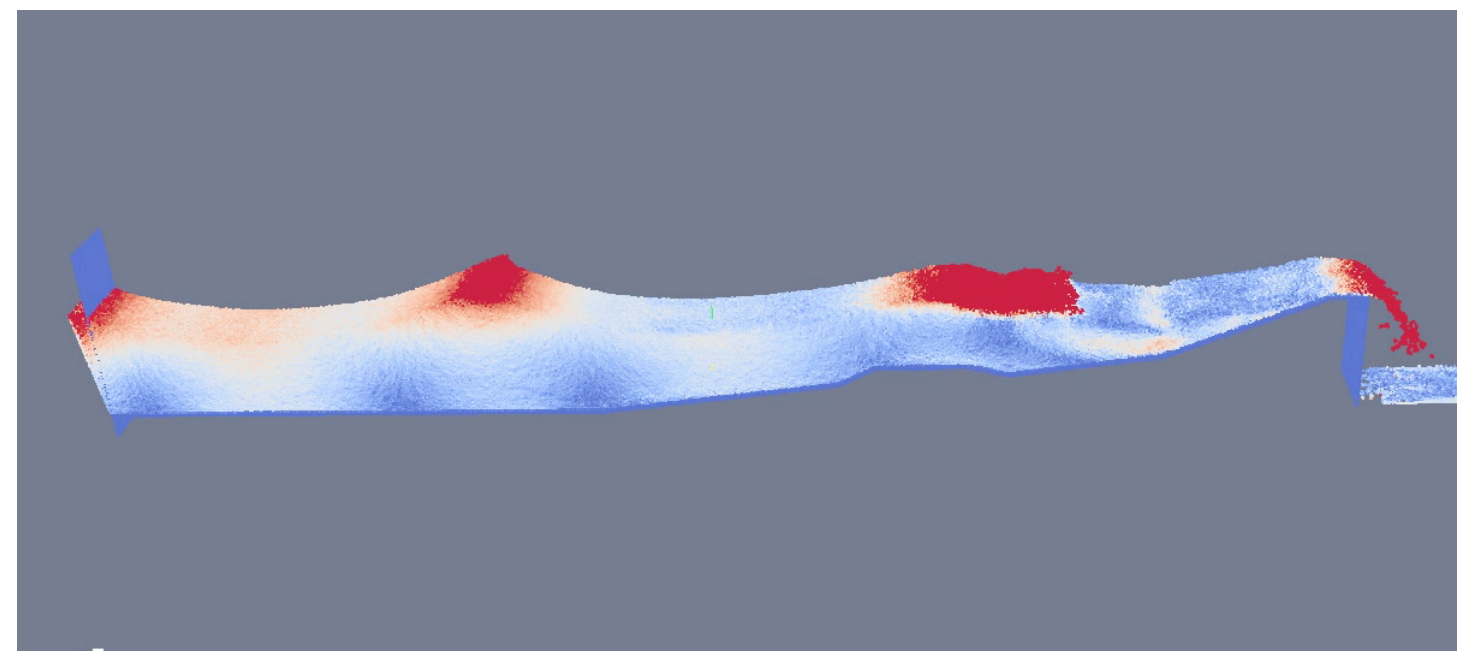

Figure 3. Overtopping conditions for the same berm conditions

\section{EXPERIMENTS OF ROOS AND BATTJES}

Results from a series of experiments on a plane slope beach were obtained by Roos and Battjes (1976) and were compared with the early analyses of Hunt. They measured both runup and velocity on the slope. There are many other experiments that could have been chosen for comparison, but this dataset seemed quite suitable for demonstrating the accuracy of the GPUSPH method for the runup problem. Problem 10 of their test series was for a slope of 0.2 , wave height of $0.183 \mathrm{~m}$ and wave period of $1.28 \mathrm{sec}$. The tank was $0.8 \mathrm{~m}$ wide with a length of $30 \mathrm{~m}$. The method they chose to determine wave runup combined four wave gages and visual observations as shown in Figure 4. They were also able to collect slope layer thickness and velocity.

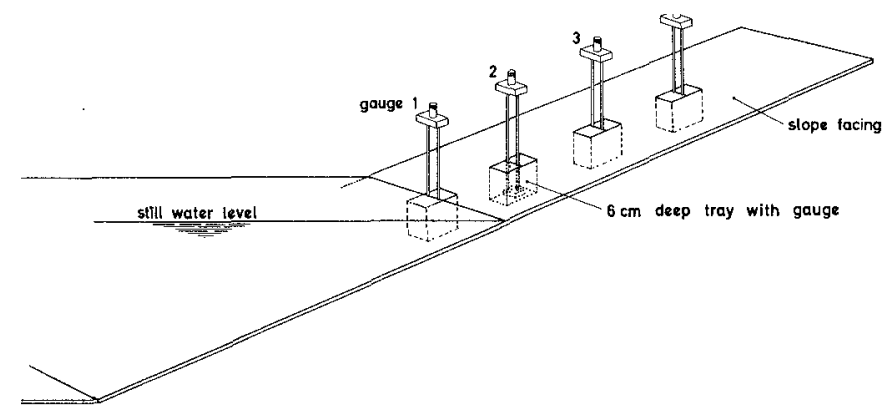

Figure 4. Layout of wave gages for Roos and Battjes (1976)

For the GPUSPH three-dimensional simulation, it was not realistic to simulate the full $30 \mathrm{~m}$-wave tank with particles small enough to provide an accurate result. Therefore it was decided to only use a numerical tank $8 \mathrm{~m}$ long and $0.6 \mathrm{~m}$ wide. For this geometry, a particle spacing of $0.012 \mathrm{~m}$ was selected giving 824,060 particles. Kinematic viscosity was used for the problem and all boundary forces were determined using the Lennard-Jones methodology. Lennard-Jones is a mathematical representation of the force potential between a pair of particles. The geometry of the GPUSPH numerical tank is shown in Figure 5. Note that the wave paddle is a flap type set into the bottom. 


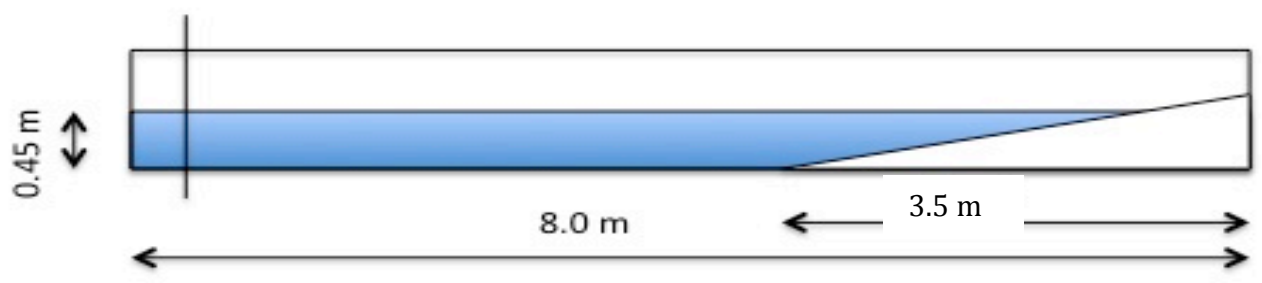

Figure 5. Layout of the numerical tank to compare with Roos and Battjes (1976)

There are several methods that can be used for numerically defining the actual runup as is the case in physical models. With a fixed grid system, a common method is to use the maximum grid point that a volume of fluid reaches to determine the maximum runup. With a meshless numerical scheme, each particle in the system has its own position determined by the forces experienced in the time preceding its current location. Therefore, in a three-dimensional result the frontal layer of fluid reaching the maximum vertical extent may not be uniform, a problem not unlike a physical wave tank. So, one method would be to determine the mean of the most landward particles. Another choice would be to visually review the animations created with the model results looking at all particles on the slope. The method finally adopted was the insertion of numerical wave gages placed every meter from 1 to 6 and then every $0.1 \mathrm{~m}$ beyond $6 \mathrm{~m}$. The results for Case 10 (Roos and Battjes, 1976) are shown below in Figure 6 in which the maximum high and minimum low water levels are given over the duration of the run. Once the initial wave reaches $2 \mathrm{~m}$ from the paddle the height (difference between the maximum and minimum) remains nearly constant until about $5 \mathrm{~m}$ and the effect of the slope continues through breaking at about $7.2 \mathrm{~m}$ and finally runup to about $7.8 \mathrm{~m}$ from the seaward end of the tank. From this figure the maximum runup is determined to be $0.135 \mathrm{~m}$. This compares well with the $0.137 \mathrm{~m}$ from Hunt and the $0.137 \mathrm{~m}$ from the physical model.

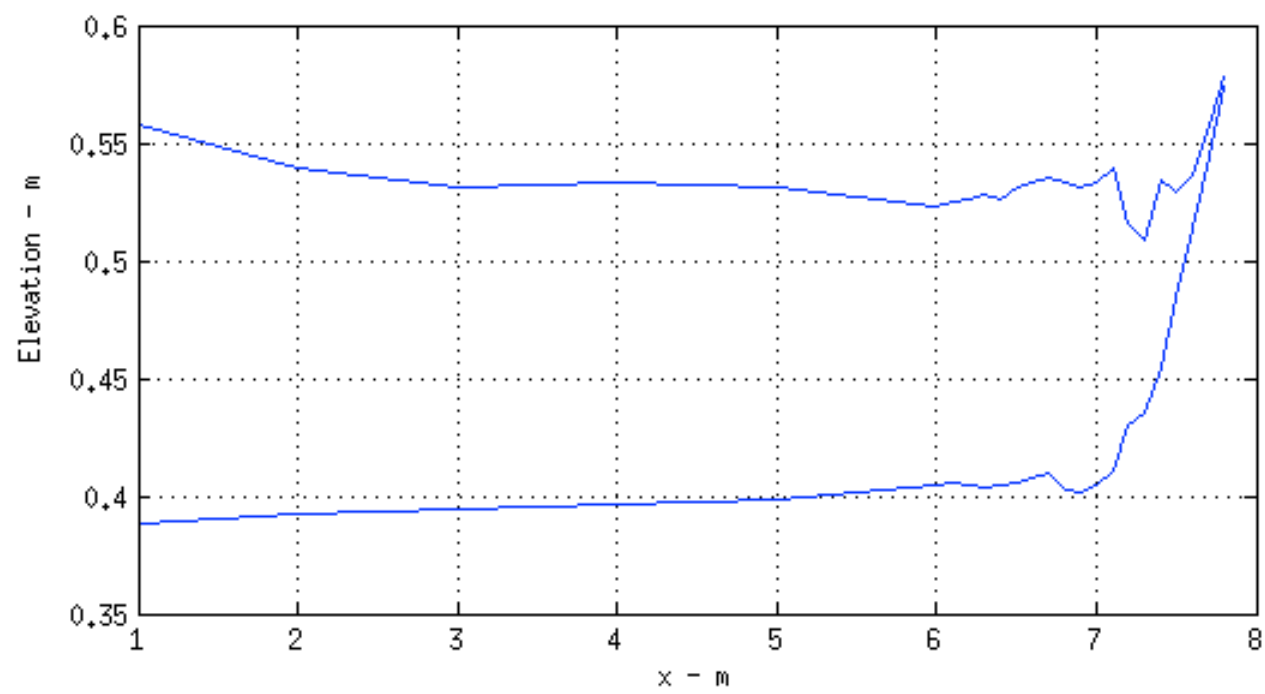

Figure 6. Wave envelope for Case 10 from

Another visualization tool for viewing the runup is shown in Figure 7 where both vertical and horizontal views are displayed synchronously. This makes it easier to determine visually the maximum runup by observing both the landward displacement of the particles as well as the thickness of the layer. This way one can determine whether it is only a particle or a layer of fluid observed when looking downward and similarly when looking across the tank. 


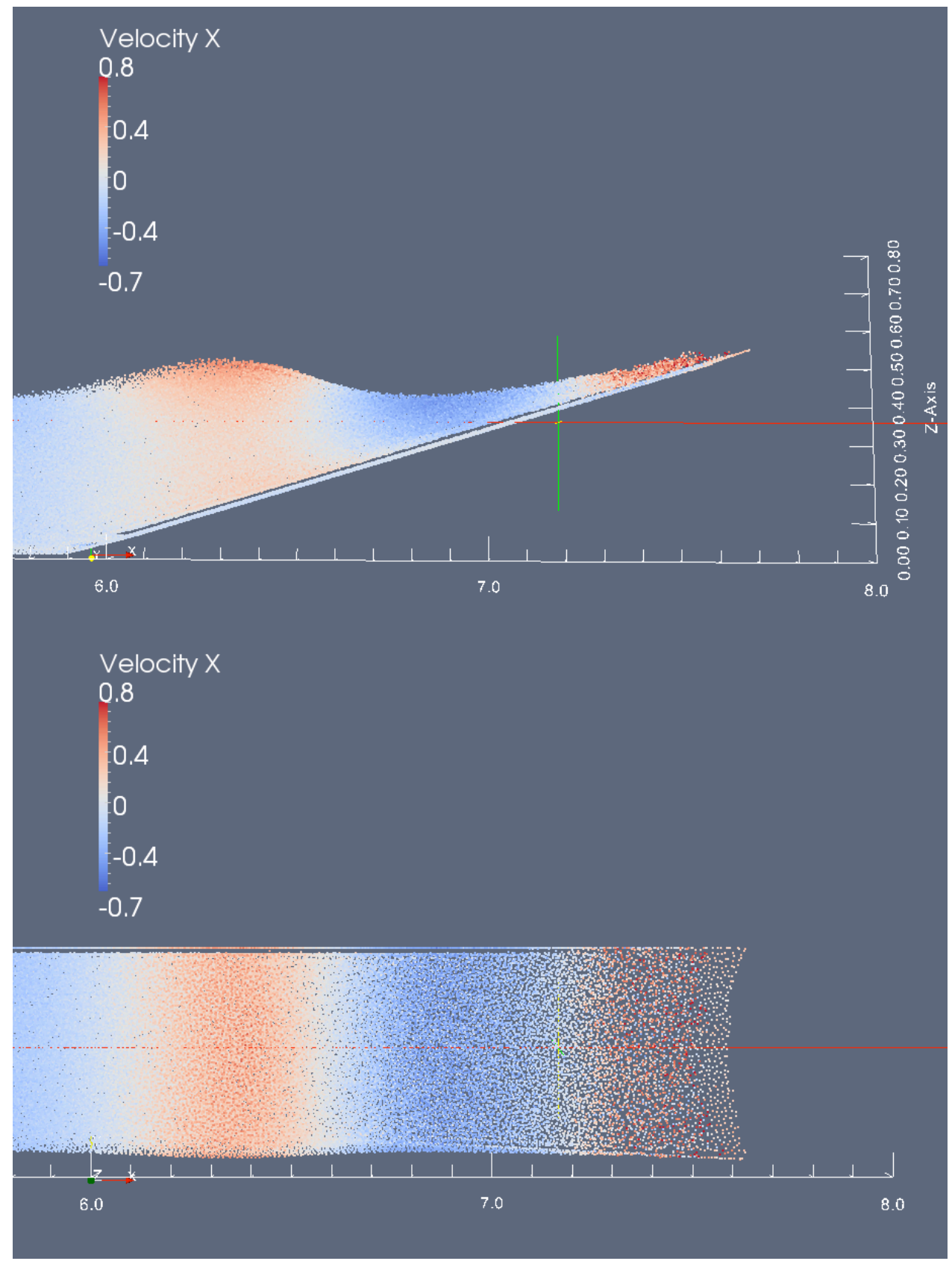

Figure 7. Vertical and horizontal views of the Case 10 run during a runup event. The velocity scale is shown to illustrate that the wave is still rushing landward.

Velocities were also computed at a location $0.05 \mathrm{~m}$ above the bed. The velocities were computed at the following distances from the end of the tank: $1 \mathrm{~m}, 3 \mathrm{~m}, 4.5 \mathrm{~m}, 5.5 \mathrm{~m}, 6.0 \mathrm{~m}, 6.5 \mathrm{~m}, 7.0 \mathrm{~m}, 7.5 \mathrm{~m}$, and $8.0 \mathrm{~m}$. Results for 3, 6 and 7 meters from the end of the tank are presented in Figure 8. The velocity results of Roos and Battjes were averaged over the thickness at the local depth whereas the velocities in Figure 8 were point results close to the bed. The numerical results are smaller than the laboratory results, likely since the measurement point in the model was very close to the boundary and the method for computing the velocity using the nearest neighbors included those particles immediately adjacent to the bed. 


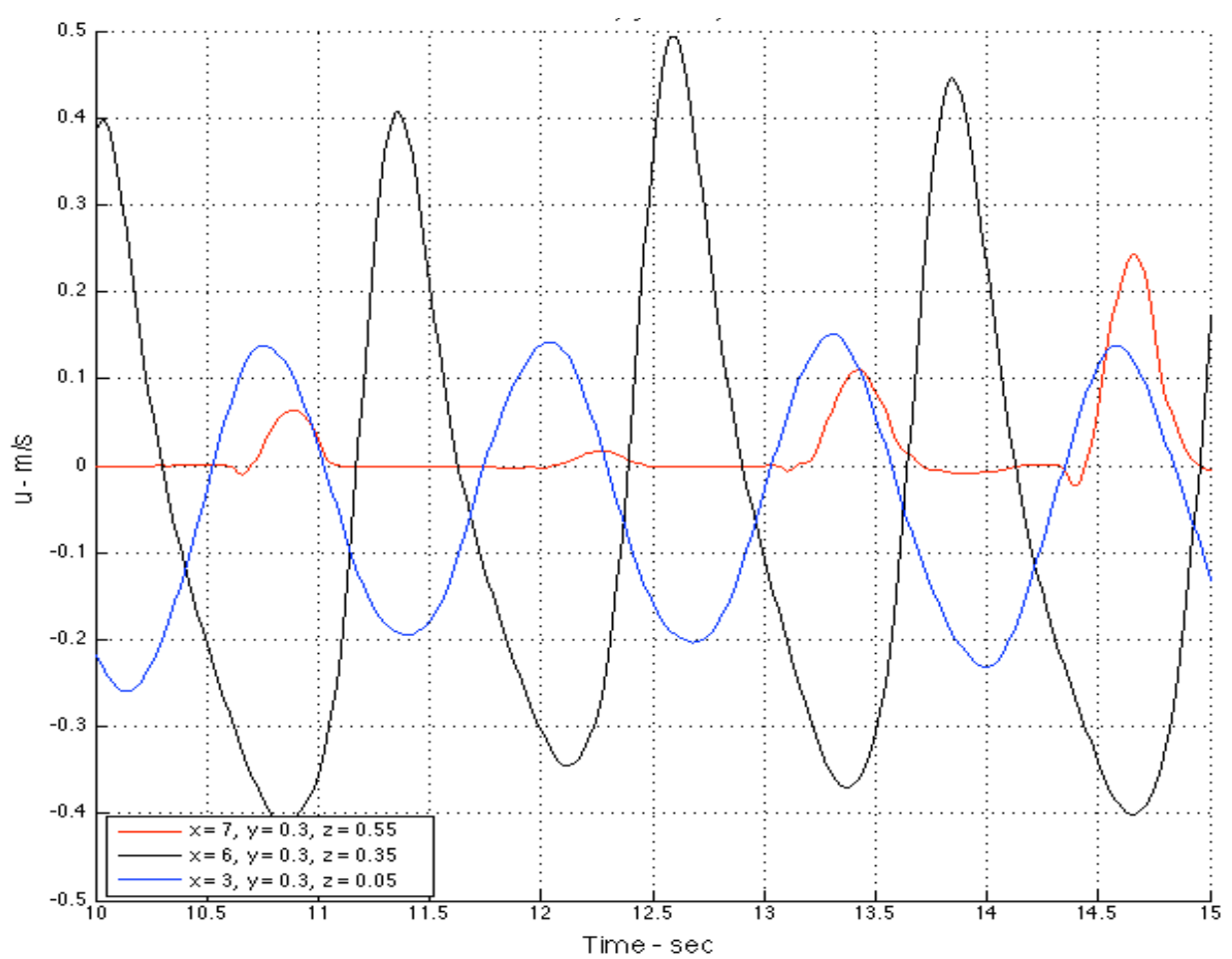

Figure 8 . Velocity over time at $3 \mathrm{~m}, 6 \mathrm{~m}$ and $7 \mathrm{~m}$ at $0.05 \mathrm{~m}$ above the bed.

\section{COMPLEX LEVEE TRANSITION}

Following hurricane Katrina, many of the levees providing hurricane protection for the City of New Orleans were rebuilt with new designs. Many of the newer designs were connected to previous designs of slightly or in some cases significantly different designs. Even in the earthen levees there were needs for transitions from the earthen levee design to an opening for traffic or a lock or to a $\mathrm{T}$ wall. These transitions do cause changes in the reflection and transformation of waves and this was factored into new designs. Figure 9 schematically illustrates the latter form of transition where the earthen levee is morphed to a T-wall atop a reduced elevation earthen levee.

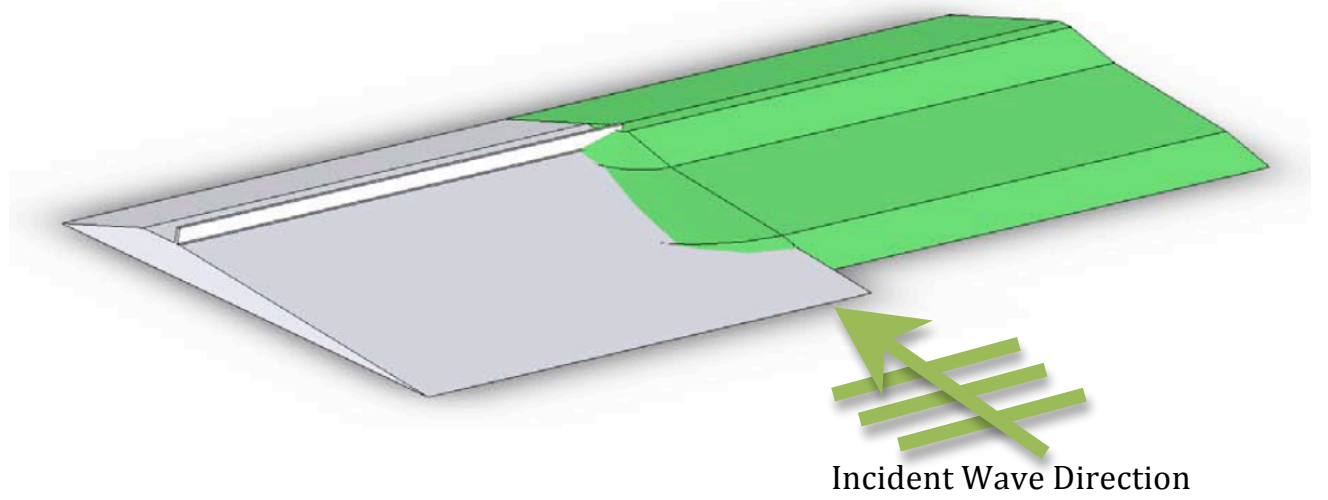

Figure 9. Schematic illustration of an earthern levee in green connecting to a levee supporting a T-wall

Figure 10 provides an example of actual dimensions for this transition located on the southern bank of Lake Pontchartrain. This illustration shows the difference in slopes and the differences in the total crest elevations. Even though there is a smooth transition planned as shown in Figure 9, there will be considerable differences in the wave overtopping, reflection and alongshore variation from the transition, not easily analyzed by simple runup computations. Both physical model testing and a Boussinesq model were used (Oaks, Edge and Lynett, 2011) to analyze the dynamics of this complex problem. 

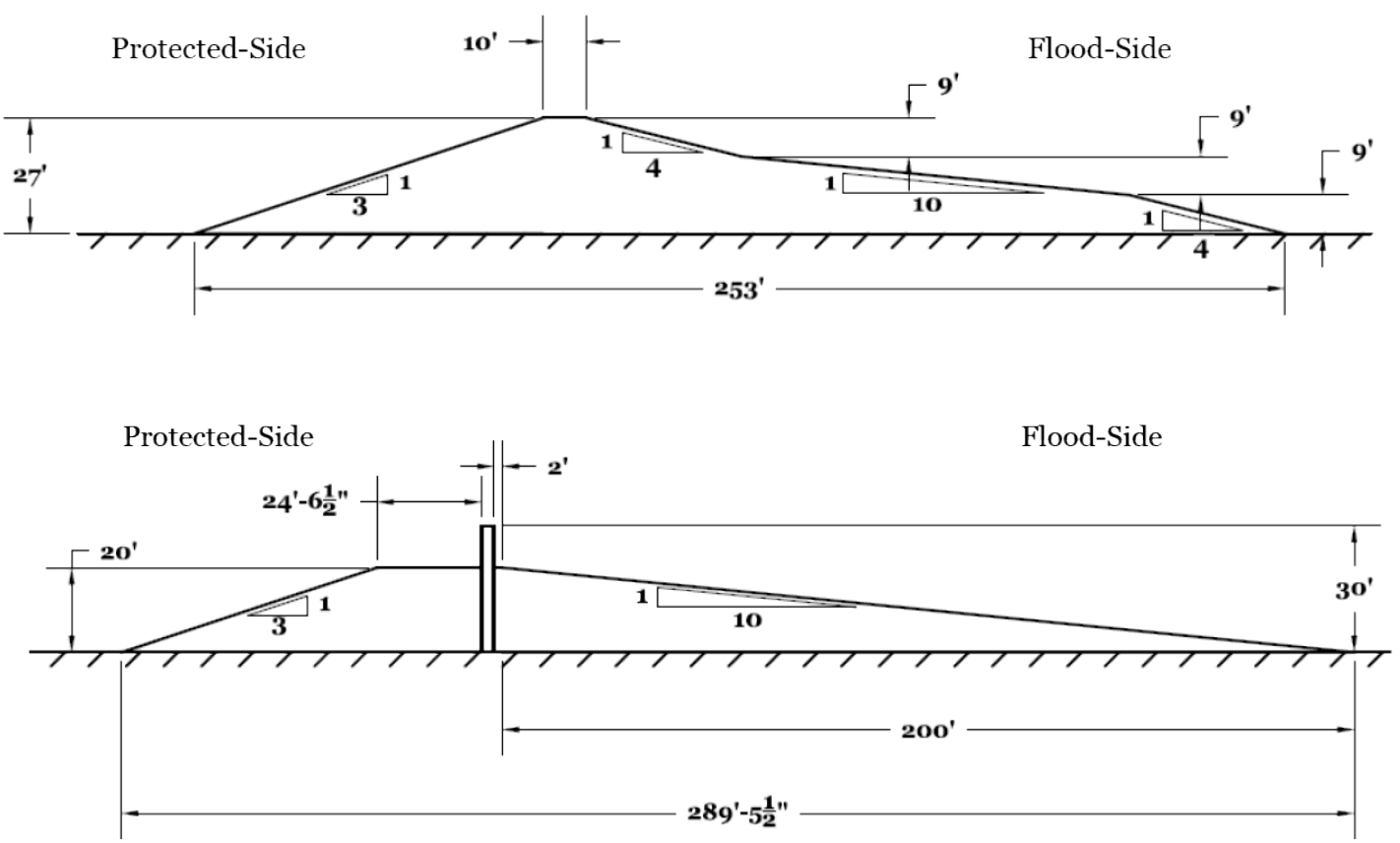

Figure 10. Schematic illustration of an earthen levee in green connecting to a levee supporting a T-wall

In the physical model tests, a length scale of $1 / 20$ was used giving a time scale of $1 / 4.45$ using the Froude number. The physical model described in Oaks, Edge and Lynette is shown in Figure 11. The numerical model is shown in Figure 12. The GPUSPH model is constructed with the same dimensions as the physical model. However, to keep the number of particles to a reasonable amount the basin in the model was $6 \mathrm{~m}$ long by $8 \mathrm{~m}$ wide. In the physical model the model was $12 \mathrm{~m}$ wide and approximately $30 \mathrm{~m}$ to the levee and then continued landward to a beach. The figure shows the beginning of the first wave and the wall and bottom of the basin. Although the bottom grid shows, it is a bottom composed of a single layer of particles with the same density as the water particles.

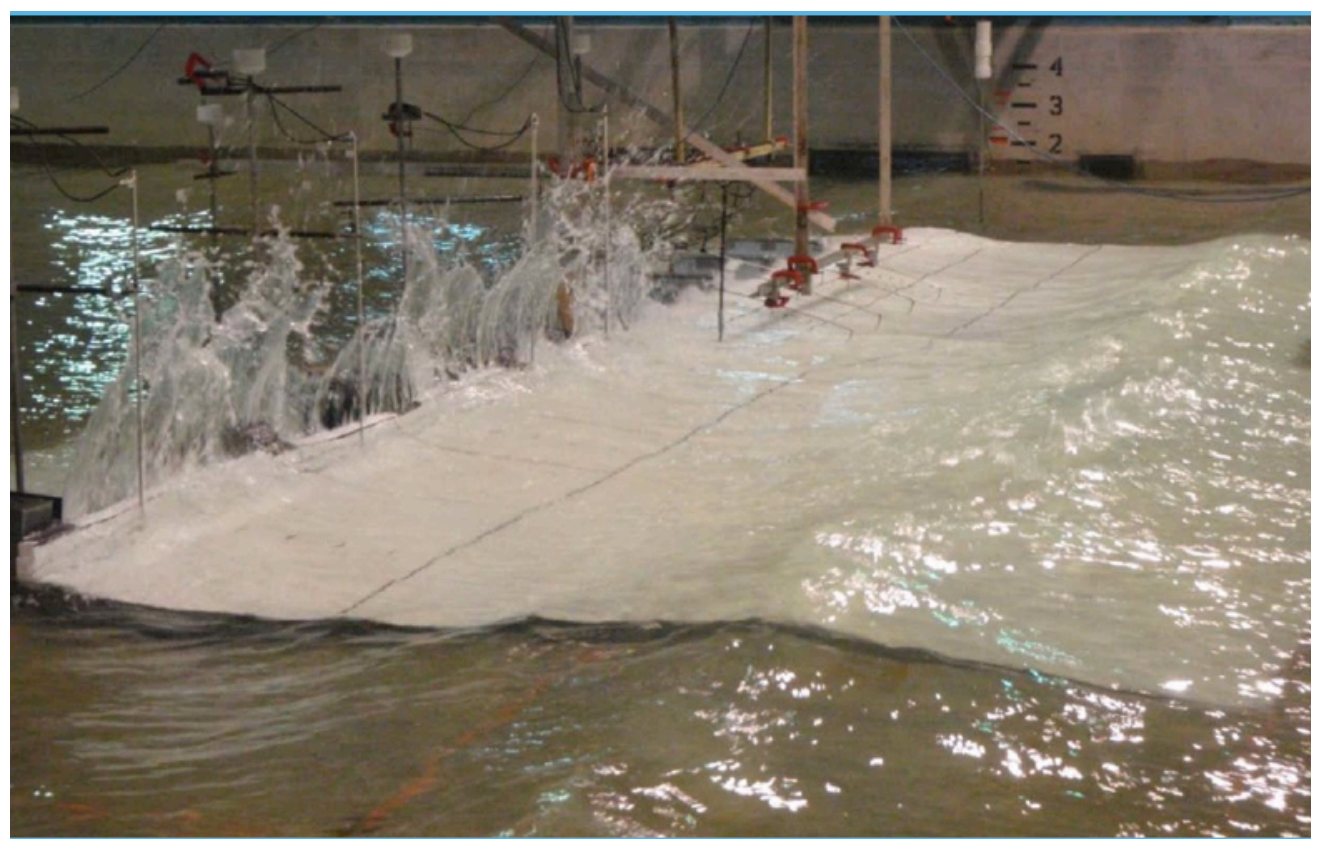

Figure 11. Physical model showing T-wall in foreground and earthen levee in the distance. Wave gages are shown in front of the wall and runup gages on the earthen levee. 


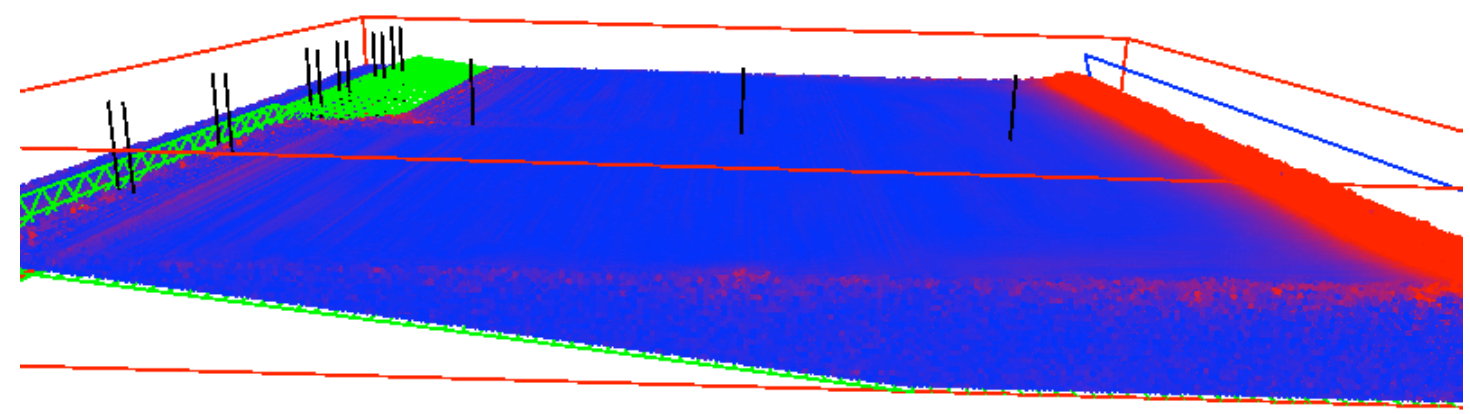

Figure 12. GPUSPH model showing T-wall in foreground and earthen levee in the distance. Wave gage pairs are shown in front of the levees and at $2 \mathrm{~m}, 4 \mathrm{~m}$ and $6 \mathrm{~m}$ from the end of the basin.

The figure below shows the model results for a wave height of $0.18 \mathrm{~m}$ with a period of $1.79 \mathrm{sec}$. As before the model uses kinematic viscosity and the Lennard-Jones force potential between particles. The bottom is placed in the model using a digital elevation model. The vertical T-wall is represented with a steep slope as opposed to a vertical wall. As a result of the sloped wall, there is not nearly as much splash as with a vertical wall. Of major importance are the effect of the transition and the effects of the different seaward slopes. The high velocity along the center of the separation of the two sides is clearly evident. Similarly, the breaking phenomena on both are quite different creating an alongshore effect as well.

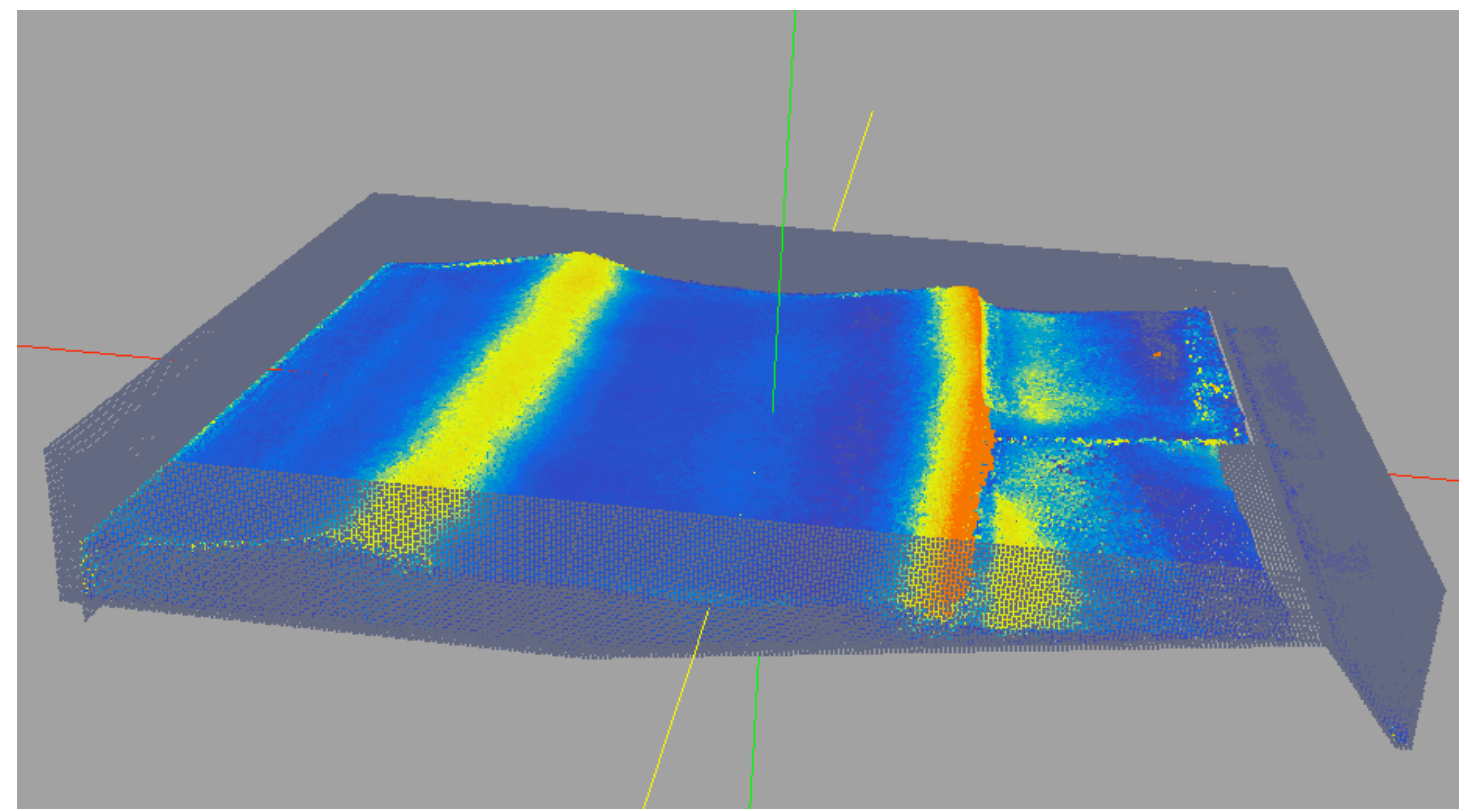

Figure 13. Results of GPUSPH model. The hotter colors represent higher velocities. Note that the levee is on the right of the figure.

Figure 14 presents wave heights from the three numerical wave gages located seaward of the levee crest at $2 \mathrm{~m}, 4 \mathrm{~m}$, and $6 \mathrm{~m}$, in the center of the basin. The latter is clearly on the slope but seaward of the crest and the $4 \mathrm{~m}$ gage is on the toe of the slope. The figure shows that the wave has broken before it reaches the position of the gage at $6 \mathrm{~m}$ from the end of the basin. Figure 15 illustrates the water levels immediately in front of the T-wall and in front of the crest of the earthen levee. The gold and magenta results are from in front of the $\mathrm{T}$-wall with the magenta being closest to the break in levee design. The other four show the times that the waves on the earthen levee reached this same distance from the end of the basin. When there was a runup on the earthen levee, the crest was at a higher elevation than the height in front of the T-wall for all but one condition. 


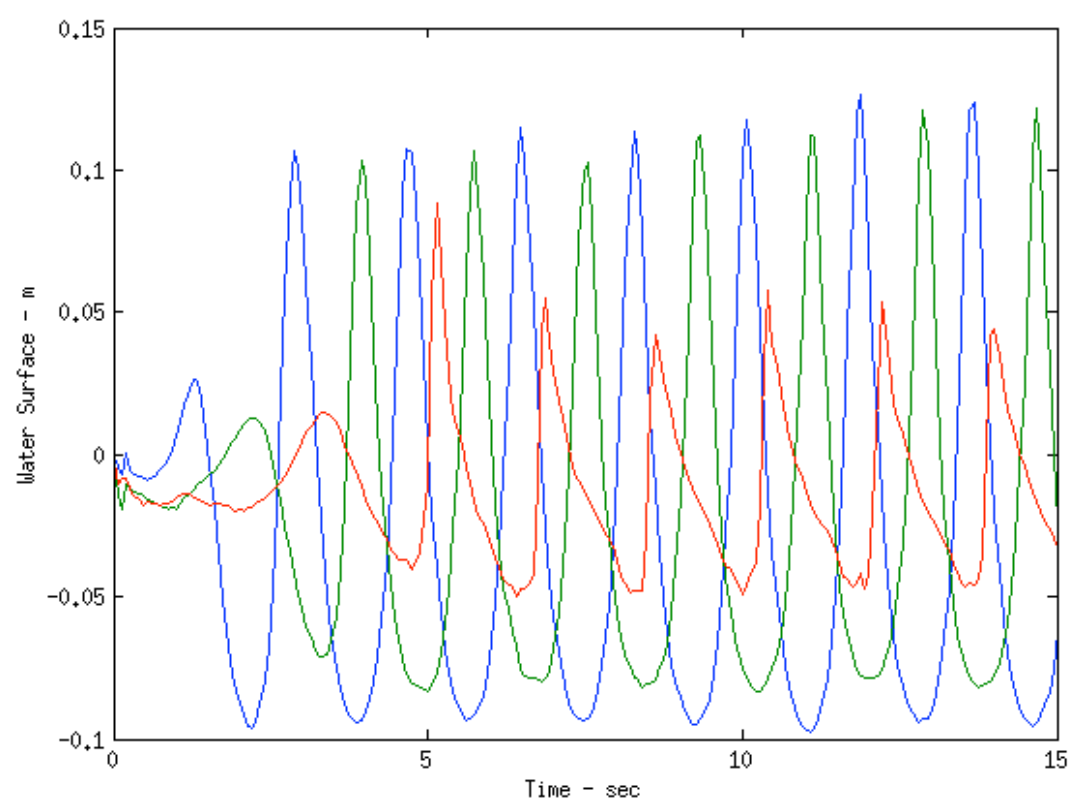

Figure 14. Water surface elevations along the centerline at $2 \mathrm{~m}, 4 \mathrm{~m}$ and $6 \mathrm{~m}$ from the end of the basin.

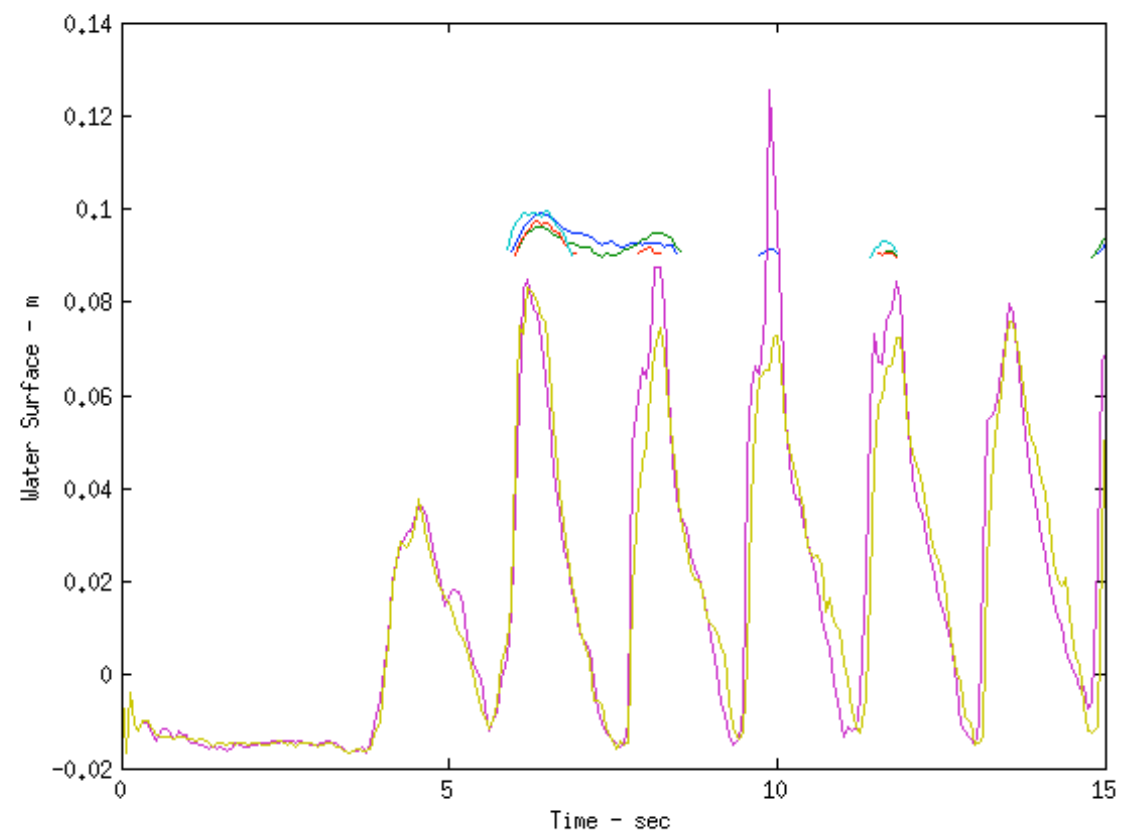

Figure 15. Water surface elevations at the crest of the levees.

\section{CONCLUSIONS}

The GPUSPH approach for numerical modeling presents opportunities for simulating difficult hydrodynamic conditions including the surf zone with breaking waves. GPUSPH also allows the incorporation of very irregular bathymetry. The model has been compared with other numerical and experimental results and has show good agreement. The Case 10 from Roos and Battjes is shown to compare very closely. A comparison with experimental work by Oaks, Edge and Lynett for a complex three-dimensional problem also presents reasonable and representative results. 
It is clear that GPUSPH does require a significant amount of time for these simulations. The simulation for the basin with 994,580 particles required 9.5 hours, model, for $20 \mathrm{sec}$, prototype, using only 382 GPU cores. When more cores are added using more recent and larger NVIDIA video cards, significant improvements will occur in processing time.

\section{ACKNOWLEDGMENTS}

The authors would like to acknowledge the contributions of the UNC-Renaissance Computing Institute and UNC-Coastal Studies Institute for supporting this work. The Office of Naval Research also contributed to the development and testing of the GPUSPH.

\section{REFERENCES}

Dalrymple R A, Rogers B D. 2006. "Numerical Modeling of Water Waves with the SPH Method". Coastal Engineering. Vol. 53. No. 2. pp 141-147.

Drake Oaks, Billy Edge, and Patrick Lynett, "Evaluation of the Structure of Levee Transitions on Wave Runup and Overtopping by Physical Modeling" accepted for publication, J.Waterways, Ports, Oceans and Coastal Engr., ASCE, Feb. 2011.

Gomez-Gesteira, M., and R. A. Dalrymple. 2004. Using a three-dimensional smoothed particle hydrodynamics method for wave impact on a tall structure, Waterway, Port, Coastal and Ocean Engineering, 130(2):63-69.

Hérault, A., G. Bilotta, and R. A. Dalrymple. 2010. SPH on GPU with CUDA, Hydraulic Research, 48 (Extra Issue): 74-79.

Monaghan, J. J. 1994. Simulating free surface flows with SPH. Computational Physics, 110:399-406.

Saville, T. 1962. An approximation of the wave run-up frequency distribution. Proceedings of $8^{\text {th }}$ ICCE, ASCE, Chapter 4.

Roos, Ary and Jurjen A. Battjes, Characteristics of Flow in Run-Up of Periodic Waves, Proceedings of $15^{\text {th }}$ ICCE, Honolulu, ASCE.

Weiss, R., A. J. Munoz, R. A. Dalrymple, A. Hérault, and G. Bilotta. 2010. Three-dimensional modeling of long-wave runup: Simulation of tsunami inundation with GPUSPH, Proceedings of $32^{\text {th }} I C C E$, ASCE. 